\title{
The Hall Technique: A Non-conventional Method for Managing Carious Primary Molars
}

Hariri $\mathbf{M}^{\star}$, Ramdi $\mathbf{H}$, El Alloussi M and Chhoul $\mathrm{H}$

Centre of Consultation and Dental Treatment of Rabat, Mohammed V University, Morocco

*Corresponding author: Hariri M, Faculty of Dentistry, Resident in Paediatric Dentistry, Centre of Consultation and Dental Treatment of Rabat, Mohammed V University, Morocco, Tel: +212668607363; E-mail: haririelmehdi@gmail.com

Rec date: June 14, 2016; Acc date: July 04, 2016; Pub date: July 12, 2016

Copyright: (c) 2016 Hariri M, et al. This is an open-access article distributed under the terms of the Creative Commons Attribution License, which permits unrestricted use, distribution, and reproduction in any medium, provided the original author and source are credited.

\begin{abstract}
The Hall Technique is a non-conventional method for managing carious primary molars. Decay is sealed under preformed metal crowns without any caries removal, tooth preparation, or local anesthesia. This case report describes the treatment strategy for early childhood caries in mandibular first primary molars, in a young patient who has 4 years old using the hall technique. The patient was followed-up for 2 years. Clinical and radiographic evaluation showed acceptable results, with no signs and symptoms of pulpal and periodontal disease.
\end{abstract}

Keywords: Hall technique; Non-conventional; Caries; Primary molars

\section{Introduction}

The Hall technique, a novel method for management carious primary molars where decay is sealed using Preformed Metal Crowns (PMCs), without any caries removal, tooth preparation or local anesthesia. This technique is named after Dr Norna Hall, a general dental practitioner from Scotland, who developed and used the technique for over 15 years until she retired in 2006. With the Hall Technique, the process of fitting the crown is quick and non-invasive.

This report describes the management of carious primary molars using the hall technique in a young patient who presented a high dental anxiety with 2 years of follow-up.

\section{Case Report}

A 4 years old young female patient presented at to the Department of Pediatric Dentistry and Prevention of Rabat University, for a global oral rehabilitation in relation with an Early Childhood Caries (ECC). Past medical history was reviewed and there was no remarkable report. The clinical examination did reveal occlusal and distal cavitated lesion in the first mandibular primary molars (74 and 84) with no hard and spontaneous pain, no clinical signs or symptoms of irreversible pulpitis or dental abscess. Intraoral exploration revealed Non-physiological mobility in both of the tooth, assessed by placing the points of a pair of tweezers in an occlusal fossa, and gently rocking the tooth buccolingually, and comparing with a healthy antimere. Intraoral periapical radiographic investigation revealed a moderate occlusal and distal lesion in the first mandibular primary molars with a band of sound dentine between the lesion and pulp and no intra-radicular pathology. Based on the clinical and radiographic findings, a diagnosis of early childhood caries with no clinical and radiographic signs or symptoms of irreversible pulpits or dental abscess was made.

After explaining and discussing with patient and parents the available treatment options with their respective advantages, disadvantages, limitation, prognosis and cost of each treatment, we opted for the non-conventional one (the hall technique) because all conventional techniques have failed with This patient who presented a high dental anxiety. They were briefed on the procedure and we explained to the young patient that crowns were like soldiers wear to protect their heads. After assessing the tooth shape, contact points/ areas and the occlusion, orthodontic separators were used to create space for fitting a Hall crown at the mesial and distal contacts. The patient was seen 3 days later for removal of the separator and the interproximal area of the gingiva was inspected. Protecting the airway was also important before the crown was placed, to ensure there will be no danger of the child inhaling or swallowing a loose crown. Different sizes of crowns were selected until we finded one which covers all the cusps and approached the contact points with a slight feeling of "spring back". Then, we loaded the crown generously with a glass ionomer luting cement from the base upwards, Fitting the crown and we did a first stage seating. After wiping the excess cement away, we checked fit and we did second stage seating. Then we removed excess cement, flossed between the contacts and checked occlusion and discharge.

\section{Discussion}

Dental caries is the most common chronic childhood disease. It is becoming increasingly clear that dental caries is a dynamic process, it is also being recognised that the dentine/ pulp complex is far from passive when exposed to dental caries $[1,2]$. Instead, these tissues mount an active defence response from the earliest stages of carious lesion formation in the enamel. Following a response from the immune system, odontoblasts are stimulated to lay down a layer of reactive dentine in an effort to distance the pulp from the approaching carious lesion, an effect readily observed, at a gross level, on radiographs. Traditional treatment of caries has been by surgical removal of the infected dental tissues, followed by restoration with a suitable filling material. This conventional dental treatment is invasive, often involving the destruction of considerable amounts of sound tooth for access to the carious lesion, particularly in interproximal sites. Moreover, conventional restorations have a limited lifetime, leading to a cycle of repeated restoration, which in turn means inefficient use of limited oral health services resources, more pulp disease and early loss of teeth [3]. The Hall technique is a minimally 
invasive restorative procedure using Preformed Metal Crowns cemented with no local anaesthesia, no caries removal and no tooth preparation. It's considererd as a less traumatic procedure from the point of view of child behaviour management $[4,5]$. This procedure manipulates the plaque's environment by sealing it into the tooth, separating it from the substrates (essentially, nutrition) it would normally receive from the oral environment. Here is a possibility that the plaque may continue to receive some nutrition from perfusion through the dentinal tubules. However, there is good evidence that if caries is effectively sealed from the oral environment, the bacterial profile in the caries changes significantly to a less cariogenic community and the lesion does not progress [6,7]. Several studies have shown that this technique is based on scientific and clinical evidence with a success rate, which is comparable to conventional therapies.

Innes conducted a randomized controlled clinical trial on teeth treated with Hall technique and others treated by conventional therapies constituting a control group, with clinical and radiographic follow-up that varies between 2 to 5 years. 132 children participated in the study and 264 primary molars were treated. The success rate in the two treating approaches is the same $[8,9]$.

Another randomized controlled clinical trial was performed by practitioners of Tayside in Scotland with a clinical and radiographic follow-up of 2 years. 132 children were selected in this study with a set of 248 treated teeth [10-12] (The Hall technique and 124 treated 124 by conventional therapies). The results of these studies are summarized in the following Table 1.

\begin{tabular}{|l|l|l|l|l|l|}
\hline & \multicolumn{2}{|c|}{ Control restorations } & \multicolumn{2}{l|}{ Hall technique } & \multicolumn{2}{l|}{$\begin{array}{l}\text { Significanc } \\
\text { e }\end{array}$} \\
\cline { 2 - 5 } & Number & $\begin{array}{l}\text { Proportio } \\
\mathbf{n}\end{array}$ & Number & $\begin{array}{l}\text { Proportio } \\
n\end{array}$ & \\
\hline Major failures & 19 & $15 \%$ & 3 & $2 \%$ & \multirow{2}{*}{$\mathrm{P}<0.001$} \\
\hline Minor failures & 57 & $46 \%$ & 6 & $5 \%$ & $\mathrm{P}<0.001$ \\
\hline Pain & 13 & $11 \%$ & 2 & $2 \%$ & $\mathrm{P} 0.003$ \\
\hline
\end{tabular}

Table 1: Performance of preformed metal crowns versus conventional restorations

The indications for using the Hall technique include teeth with proximal (Class II) lesions, cavitated or non-cavitated, occlusal (Class I) lesions, non-cavitated if the patient is unable to accept a fissure sealant or conventional restoration, occlusal (Class I) lesions, cavitated if the patient is unable to accept partial caries removal technique or a conventional restoration [11]. Contra-indications include teeth with signs or symptoms of irreversible pulpitis or dental sepsis, Clinical or radiographic signs of pulpal involvement or periradicular pathology crowns that are so broken down they would be considered unrestorable with conventional techniques $[13,14]$. The treatment described in the present case report is reasonably simple, while restoring function with a very conservative and non-invasive approach. It included the use of orthodontic separators to create space for fitting a Hall crown (74 and 84 ) followed by protecting the airway using a gauze swab square, which can be placed between the tongue and the tooth where the crown is to be fitted. After selecting the correct size, the crown was loaded generously with glass ionomer luting cement, then fitted and a first stage was seating. The excess cement away was wiped and a second stage was seating.
At last, we did a final clearance of cement, checked occlusion and discharge. Anecdotally, preformed metal crown placed high in occlusion do not cause problems for children and avoidance of interferences of $>1.5 \mathrm{~mm}$ are recommended. It has been suggested that interferences $<1 \mathrm{~mm}$ are well tolerated with dento-alveolar compensation occurring within a few weeks. The inevitable increase in Vertical Dimension of Occlusion (VDO) and the premature contacts were resolved fully at 1 year. Anecdotally, re-equilibration occurred within 2 weeks. There were no reported symptoms of occlusal dysfunction or Temporomandibular Disorders (TMD), although the children were not specifically examined for either. It has also been noted that the increase in VDO resulting from the use of bites planes for orthodontics did not increase the risk of TMD. This lack of symptoms is attributed to children's considerable capacity for dentoalveolar compensation. In summary, young children appear to have an adaptable masticatory system in which changes occur quickly. As with all restorative techniques, following-up is of critical importance. The patient should be seen at 3,6, and 12 months and yearly for 5 years. Pulpal and periodontal status should be confirmed both clinically and radiographically at these control visits.

In this case after 2 years, clinical and X-ray examinations showed satisfactory functional outcomes and a good state of pulpal and periodontal health as shown in Figures1-3.

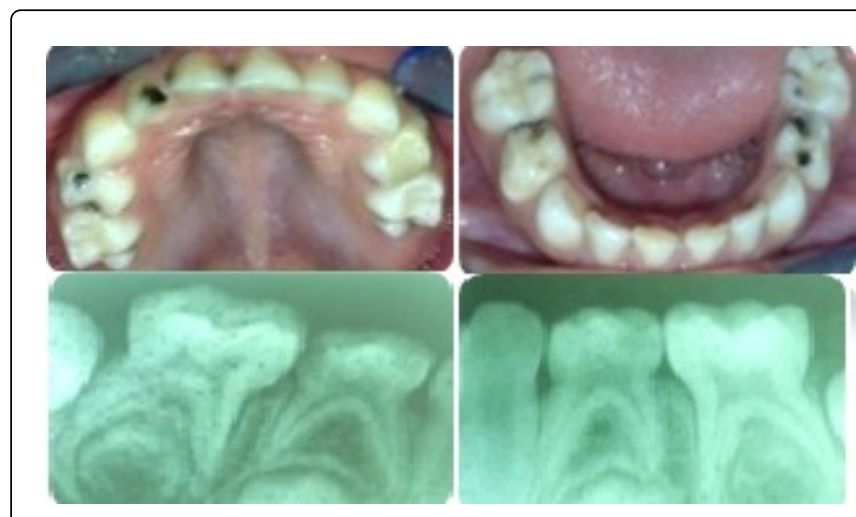

Figure 1: Intraoral periapical x-ray of first maxillar and mandibular molars (74 and 84).

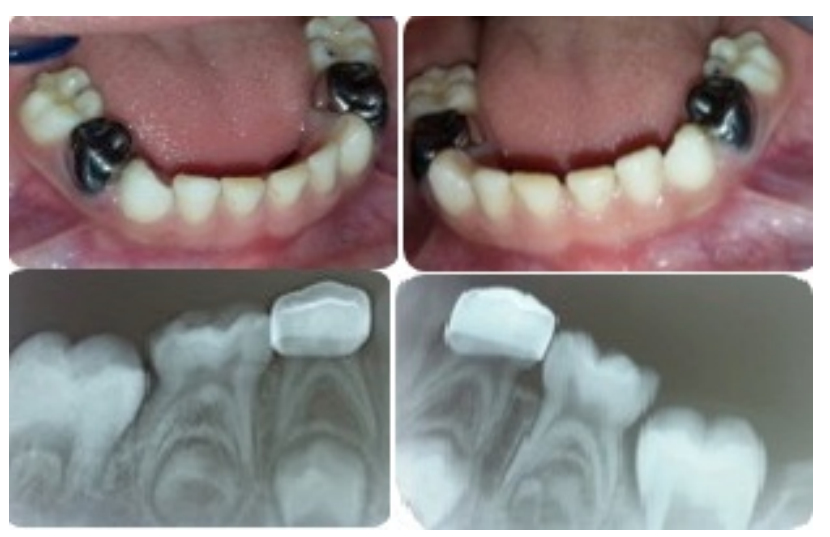

Figure 2: Clinical and radiographic follow-up after 12 months. 
Citation: Hariri M, Ramdi H, El Alloussi M, Chhoul H (2016) The Hall Technique: A Non-conventional Method for Managing Carious Primary Molars. Dentistry 6: 385. doi:10.4172/2161-1122.1000385

Page 3 of 3

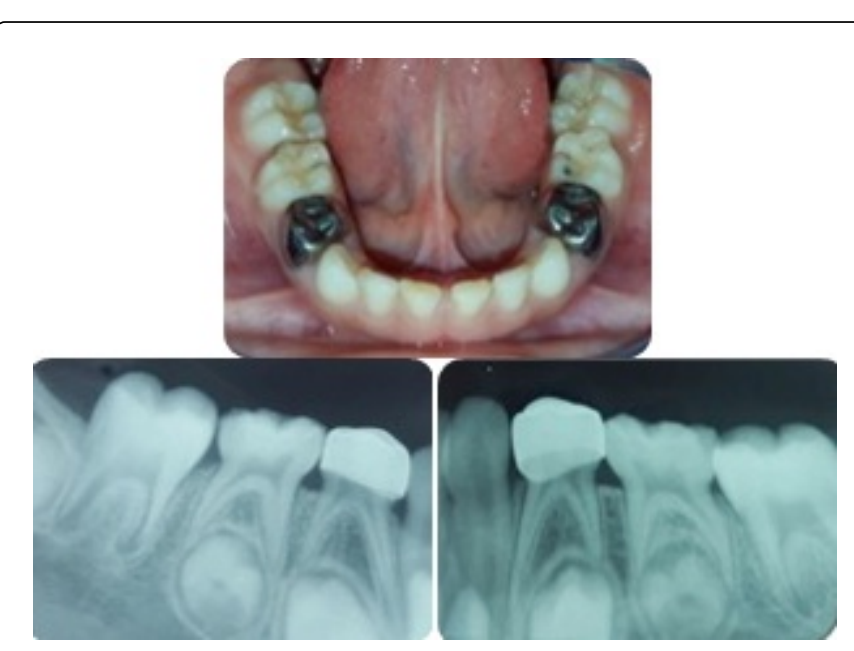

Figure 3: Clinical and radiographic follow-up after 2 years.

\section{Conclusion}

The Hall Technique is a non-conventional technique for managing carious primary molars, and it is not the answer to the problem of childhood dental caries. Dental cavities are the consequence of the disease of dental caries, and should not be confused with the disease itself. Fitting a Hall crown to a child may well manage the problem of the cavity, but it will do nothing to sort the problem of the disease; the child will develop further cavities in other teeth if nothing else changes. However, the Technique does offer another method of managing the early to moderately advanced active dentinal lesion in primary molars, with good evidence of effectiveness, and acceptability to children and parents. This evidence aligns with the positive findings of other studies of biological strategies for managing caries in primary teeth.

\section{References}

1. Foster AL, Boyd DH, Davidson SE, McKay KS, Thomson WM, et al. (2004) Acceptability of the technical Hall to relatives and children. New Zealand Dental Journal 110: 12-17.
2. Innes NPT, Evans DJP (2013) Modern Approaches to caries management of the primary dentition. Br Dent J 214: 11.

3. Evans DJP, Innes NPT, Stirrups DR (2006) Longevity of Hall Technique crowns compared with conventional restoration for primary molars; 2 year results. Br Dent J 40: 327.

4. Innes NP, Evans DJ, Stirrups DR (2011) Sealing caries in primary molars: randomized control trial, 5 year results. J Dent Res 90: 1405-1410.

5. Innes NP, Evans DJ, Stirrups DR (2007) The Hall Technique: A randomized controlled Clinical trial of a novel method of managing carious primary molars in general dental practice: Acceptability of the technical and outcomes at 23 months. BMC Oral Health 7: 18 .

6. Innes NPT, Stirrups DR, Evans PDI, Hall N, Leggate M (2006) A novel technique using preformed metal crowns for managing carious primary molars in general practice: A retrospective analysis. Br Dent J 200: 451-454.

7. Dean AA, Bark JE, Sherriff A, Macpherson LM, Cairns A (2011) Use of the technical Hall for management of carious primary molars Among Scottish general dental Practitioners. Eur Arch Paediatr Dent 12: 159-162.

8. Bell SJ, Morgan AG, Marshman Z, Rodd HD (2010) Child and parental acceptance of preformed metal crowns. Eur Arch Paediatr Dent 11: 218-224.

9. Van der Zee V, van Amerongen WE (2010) Short Communication: Influence of preformed metal crowns (Technical Hall) on the occlusal vertical dimension in the primary dentition. Eur Arch Paediatr Dent 11: 225-227.

10. McDowell EH, Baker IM (1991) The skeletodental adaptations in deep bite correction. Am J Orthod Dentofacial Orthop 100: 370-375.

11. Kindelan SA, Day P, Nichol R, Willmott N, Fayle SA (2008) UK National Clinical Guidelines in Paediatric Dentistry stainless steel preformed crowns for primary molars. Int J Paediatr Dent 18: 20-28.

12. Baba K, Tsukiyama Y, Clark GT (2000) Reliability, validity, and utility of various occlusal measurement methods and techniques. J Prosthet Dent 83: 83-89.

13. Randall RC, Vrijhoef MM, Wilson NH (2000) Efficacy of preformed metal crowns vs. amalgam restorations in primary molars: a systematic review. J Am Dent Assoc 131: 337-343.

14. Roberts JF, Attari N, Sherriff M (2005) The survival of resin modified glass ionomer and stainless steel crown restorations in primary molars, placed in a specialist paediatric dental practice. Br Dent J 198: 427-431. 